\title{
Urodimento
}

REVISTA DE ESTUDOS EM ARTES CÊNICAS

E-ISSN 2358.6958

\section{Joana Paula Manso de Noronha: Uma dramaturga no teatro brasileiro do século XIX (1840-1859)}

\author{
Elizabeth Ribeiro Azevedo
}

Para citar este artigo:

AZEVEDO, Elizabeth Ribeiro. Joana Paula Manso de Noronha: uma dramaturga no teatro brasileiro do século XIX (1840-1859). Urdimento - Revista de Estudos em Artes Cênicas, Florianópolis, v. 2, n. 41, set. 2021.

do) DOI: http:/dx.doi.org/10.5965/1414573102412021e0203

Este artigo passou pelo Plagiarism Detection Software | iThenticate 
Joana Paula Manso de Noronha:

Uma dramaturga no teatro brasileiro do século XIX (1840-1859)

Elizabeth Ribeiro Azevedo ${ }^{1}$

\section{Resumo}

Este artigo apresenta a argentina Juana (Joana) Paula Manso de Noronha no período em que viveu no Rio de Janeiro, entre 1840 e 1859, e atuou como jornalista, romancista, educadora, mas principalmente como dramaturga e atriz. Joana trabalhou no Teatro São Pedro de Alcântara e no Ginásio Dramático. Escreveu quatro peças entre dramas e comédia, podendo ser considerada a primeira dramaturga "brasileira" de relevância na história do teatro nacional.

Palavras-chaves: Teatro e música. Dramaturgia brasileira. Francisco de Sá Noronha.

Joana Paula Manso de Noronha:

A playwright in 19th century Brazilian theatre (1840-1859)

\section{Abstract}

This article presents the Argentine Juana (Joana) Paula Manso de Noronha during the period she lived in Rio de Janeiro, between 1840 and 1859, and worked as a journalist, educating, novelist, but mainly as a playwright and actress. Joana worked at the São Pedro de Alcântara Theater and at the Ginásio Dramático. She wrote four plays between dramas and comedy, and can be considered the first "Brazilian" female playwright of relevance in the history of national theater.

Keywords: Theatre and music. Brazilian dramaturgy. Francisco de Sá Noronha.

Joana Paula Manso de Noronha:

Una dramaturga en el teatro brasileño del siglo XIX (1840-1859)

\section{Resumen}

Este artículo presenta a la argentina Juana (Joana) Paula Manso de Noronha durante el período que vivió en Río de Janeiro, entre 1840 y 1859, y trabajó como periodista, novelista, educadora, pero principalmente como dramaturga y actriz. Joana trabajó en el Teatro São Pedro de Alcántara y en el Gimnasio Dramático. Escribió cuatro obras entre dramas y comedia, que puede considerarse la primera dramaturga "brasileña" de relevancia en la historia del teatro nacional.

Palabras clave: Teatro y música. Dramaturgia brasileña. Francisco de Sá Noronha.

1 Professora Livre Docente Senior na Escola de Comunicações e Artes (ECA) da Universidade de São Paulo. Desde 2004 tem atuado na área de documentação sobre o teatro paulista coordenando o Centro de Documentação Teatral (CDT) da ECA/USP. bethazevedo@usp.br

(9) http://lattes.cnpq.br/5086642075315709 (iD https://orcid.org/0000-0003-2583-2615 
O crítico e pesquisador do teatro Décio de Almeida Prado disse certa vez que entre o século XIX e XX muitos dos escritores e jornalistas brasileiros passaram por "aventuras teatrais", isto é, a dramaturgia não se constituiu na parte mais importante de suas obras, ainda que em alguns casos, do ponto de vista do teatro, elas tenham sido bastante relevantes. Parece que no caso de Joana Paula Manso de Noronha o mesmo tenha acontecido por razões bastante especiais.

O nome de Juana, ou Joana, Paula Manso de Noronha é bem pouco, ou quase nada, conhecido nos estudos de história do teatro brasileiro. Em geral, sua reputação fica restrita, no Brasil, às pesquisas sobre a história do jornalismo ou da educação. Isto se explica pelo fato de Joana ter sido a segunda editora no Brasil, a primeira de um jornal na corte, de maior repercussão, o Jornal das Senhoras, além de ter-se engajado na defesa dos direitos femininos, sobretudo quanto ao acesso à educação. Por sua luta contra a discriminação contra as mulheres, Joana é reconhecida como uma das primeiras feministas das Américas. De fato, sua atuação extrapolou as fronteiras de sua pátria, a Argentina. Sua vida de exilada política levou-a a viver no Uruguai, no Brasil, em Cuba e nos Estados Unidos. Nesse âmbito, porém, sua ligação com o teatro é muito pouco conhecida e nada estudada.

Sobre sua vida no Brasil, quase nada se sabe. Em geral, a bibliografia apenas menciona as peças de teatro que escreveu, como um apêndice à sua produção de jornalista. Porém, do ponto de vista da história do teatro brasileiro, é importante resgatar sua presença e sua produção em terras brasileiras. Suas obras foram apresentadas ao longo dos anos de 1840, 1850 e até depois disso, em Salvador (BA), em Rio Grande (RS) e no Teatro de São Pedro de Alcântara, no Rio de Janeiro (na corte), por diversas companhias.

Joana de Paula Manso nasceu em Buenos Aires, em 26 de junho de 1819. Seu pai, José Maria Manso, era engenheiro, um liberal engajado nas lutas pela independência do país e membro do partido unionista, agrupamento político que se opunha aos federalistas, representantes das oligarquias agrárias. Mas o que era, de início, uma disputa sobre a forma de se administrar a nova república transformou-se, pelo lado unitarista, em reivindicação de caráter social contra os privilégios monopolizados pelos federalistas. As idas e vindas da maré política 
levaram ao governo autoritário do general Juan Manuel Rosas (1793-1877), que dirigiu a Argentina entre 1835 e 1852. José e até mesmo Joana, que começara a publicar poemas na imprensa de Buenos Aires, passaram então a ser vigiados pelo regime. Para fugir às perseguições do governo, a família decidiu refugiar-se no Uruguai, em Montevidéu, em 1838, onde já vinha se formando um grupo de exilados argentinos. Joana integrou a oposição a Rosas, participando dos atos de protesto, angariando fundos e ajudando a confeccionar uma bandeira para os resistentes.

Joana Manso teve uma formação incomum para uma jovem de sua época, aprendendo línguas, história, ciências e literatura. Não é por acaso que percebeu a importância dos estudos e lutou toda sua vida pelo direito à educação para as mulheres. Durante seu exílio em Montevidéu, fundou o primeiro colégio para meninas, El Ateneo de Señoritas, em 1841. Poucos anos depois, quando a família teve que fugir também do Uruguai e instalar-se no Rio de Janeiro, criou o Colégio Santa Clara, que existiu até 1843.

Em 1845, Joana Manso casou-se com o músico português radicado no Brasil, Francisco de Sá Noronha². Juntos viajaram durante algum tempo pelos Estados Unidos e $\mathrm{Cuba}^{3}$, até estabelecerem-se de volta à corte em 1852. Joana criou então sua própria publicação, o Jornal das Senhoras, dizendo que já era tempo de aparecer "[...] um jornal redigido por senhoras a exemplo do que se pratica em todos os países civilizados da Europa e América do Norte: a ilustração, em progresso, do homem brasileiro, deve também ser partilha da mulher, porque é ser que tem alma e alma, e pensa como ele" (Jornal do Comércio, 21 de dezembro de 1851, p.4). A publicação anunciava sessões sobre modas (com moldes e riscos de bordados), artes, literatura, economia doméstica, viagens, biografias, resenhas teatrais e de romances ${ }^{4}$ e, sobretudo, temas ligados ao lugar da mulher na

${ }^{2}$ Francisco de Sá Noronha (Guimarães,1820 - Rio de Janeiro,1881). Foi um importante violinista e compositor português que desembarcou no Brasil em 1838 e participou intensamente da vida teatral da corte. Pode ser considerado o introdutor do vaudeville no país, através de suas composições originais para as traduções de peças francesas desse gênero. Também foi um dos pioneiros na criação da ópera nacional portuguesa. Para conhecer sua obra, ver Luísa Cymbron (2019).

${ }^{3}$ Nesse período, Joana escreveu um oratório, musicado por Francisco, com o título Columbus, e uma peça em versos, El huérfano.

${ }^{4}$ Em um dos números, desculpa-se por não poder traduzir e publicar o novo romance $A$ dama das Camélias, pois o original tinha se extraviado a caminho do Brasil. Vale no entanto o registro de que a publicação pretendia estar atualizada com as novidades da literatura contemporânea. 
sociedade. Destaquem-se a sessão teatral e a rubrica musical, esta última a cargo de Francisco e de H. Ch. Stokmeyer ${ }^{5}$, propondo-se a falar de modinhas brasileiras e lundus. Por diversas vezes, Francisco publicaria suas obras no jornal.

Joana deu continuidade à sua produção ficcional, concluindo seu romance mais famoso, Misterios del Plata, iniciado ainda durante sua viagem pela América e do qual traduziu os primeiros capítulos para o português para publicá-lo no Jornal. Também escreveu um outro romance, denunciando os horrores da escravidão no Brasil, chamado A família do comendador , obra sempre comparada à Cabana do Pai Tomás, sucesso internacional da escritora norte-americana, Harriet Beecher Stowe, de 1852. Já Os mistérios do Prata, vincula-se à linha de romances, peças e contos derivados do gigantesco sucesso de Os mistérios de Paris, novela de Eugène Sue, de 1849?.

A primeira incursão de Joana no teatro brasileiro de que se tem conhecimento só foi possível de ser identificada retroativamente. Em 1871, quando Joana já tinha deixado o Brasil havia décadas, o mais prestigiado ator cômico brasileiro, Francisco Correa Vasques, anunciou sua participação na peça O reinado das mulheres ou $O$ mundo às avessas, com tradução da "Ex. a Sr. Noronha"8. A peça não era uma novidade nos palcos cariocas, uma vez que havia estreado em 1844 no Teatro de São Pedro de Alcântara. Na ocasião, não foi divulgado o nome da tradutora, fato absolutamente normal na época. Tratava-se da tradução do vaudeville com danças francês em dois atos: Le royaume des

${ }^{5}$ Christiano Stockmeyer Junior (?-?). Filho de ricos imigrantes alemães no Brasil (seu pai foi cônsul de Bremen na corte), estudou música na Europa, de onde retornou por volta de 1852. Compositor pouco estudado, atribui-se a ele a introdução da música de concerto alemã no país, principalmente de Beethoven, Mozart, Weber e Schubert, em um histórico concerto em 1854 com a Sociedade Germânica Sängerbund, que ele presidia. Stockmeyer continuou organizando e participando de concertos públicos nos anos seguintes junto à companhia de ópera nacional. Além de obras menores, algumas publicadas no Jornal das Senhoras, José de Alencar the atribuiu a composição de uma ópera com o título de O sebastianista.

${ }^{6}$ Na revista $A$ Imprensa, publicou o folhetim A mulher do artista, entre outubro e dezembro de 1852 (em dez capítulos), e os primeiros quatro capítulos de A família do Comendador, entre janeiro e fevereiro de 1853.

${ }^{7}$ Ver Schapochnik (2017).

${ }^{8} \mathrm{Na}$ Companhia do ator Furtado Coelho no Teatro São Luiz no Rio de Janeiro. A obra foi apresentada como opereta em três atos, sendo que o primeiro era de criação de Vasques e os dois últimos de tradução de Joana. Também foi anunciada na mesma ocasião como Ópera-cômica. O destaque aqui é que as músicas são creditadas a Jacques Offenbach e não a Francisco Noronha como na década de 1840. É preciso não confundir essa peça com a que na década de 1860 o mesmo Vasques encenou, com grande aparato, anunciando também canções do compositor alemão: um drama fantasioso em 5 atos chamado $A$ rainha crinolina ou o reino das mulheres, do mesmo Cogniard. 
femmes, ou le monde à l'envers, de Charles Desnoyer e Theodore Cognard, de 1833. Não há parecer do Conservatório Dramático Brasileiro (CDB), mas a imprensa criticou a obra, classificada como farsa "[...] insípida, grosseira e asnática (ajuntemthe todos os sinônimos); palhaçada de uma estupidez que mete nojo (...)" (Diário do Rio de Janeiro, 19 de agosto de 1844, p.4). Posteriormente, em 1851, o mesmo empresário teatral tentou levar novamente a peça à cena, justamente quando Joana retornava ao Rio, mas o Conservatório vetou o texto, tachando-o de imoral. Portanto, a peça não subiu ao palco nessa ocasião. É possível que Joana tenha traduzido outras obras, mas a prática corrente de não se registrar o nome dos tradutores dificulta imensamente a identificação.

Um hiato na produção teatral brasileira de Joana ocorreu até sua volta da América do Norte. Passando inicialmente pela capital da Bahia, estreou sua primeira obra original, A família Morel. A peça também tem base em Os mistérios de Paris, até mais diretamente do que seu romance. Isto porque, reutiliza os mesmos personagens e acontecimentos, transcrevendo-os para a forma dramática. Trata-se do episódio de A família Morel. Na verdade, o próprio romance, como um todo, já tinha sido transposto para o palco, em cinco atos e 11 quadros, na versão de Dinaux ${ }^{9}$ e do próprio Sue, em $1844^{10}$.

A peça foi montada pelo Teatro São João, de Salvador, antes de a família ${ }^{11}$ se transferir para o Rio Grande do Sul, onde teve lugar uma pequena temporada no Teatro Sete de Setembro, na cidade de Porto Alegre, apresentando os espetáculos: Cosimo, o príncipe caiador, A graça de Deus e, novamente, a loucuradramática vaudeville em dois atos, o reinado das mulheres ou o mundo às avessas, todos com música de Noronha. Em 5 de maio de 1850, encenou-se $A$ família Morel. A crítica local destacou que este era "o episódio mais sublime do romance" (Os mistérios de Paris) tendo o segundo ato provocado uma comoção lacrimosa na plateia (O Rio Grandense, 4 de maio de 1850, p.3). Poucas semanas depois, outro vaudeville, em três atos, com música Francisco, intitulado Joaninha.

\footnotetext{
9 Pseudônimo de Prosper-Parfait Goubaux (1795-1859).

${ }^{10}$ No Brasil foi encenado também pela companhia do Teatro de São Pedro de Alcântara em março de 1851.

${ }^{11}$ O casal teve duas filhas: Eulália, nascida nos Estados Unidos em 1846 e Ermínia, nascida em Cuba em 1848.
} 
A seguir, novo vaudeville com composições de Noronha, Jacques, o corsário. Não há confirmação de que os textos, ou traduções, sejam de Joana ${ }^{12}$.

Figura 1 - Provavelmente a fachada original do Teatro Sete de Setembro. Gravura de 1847 de autor desconhecido

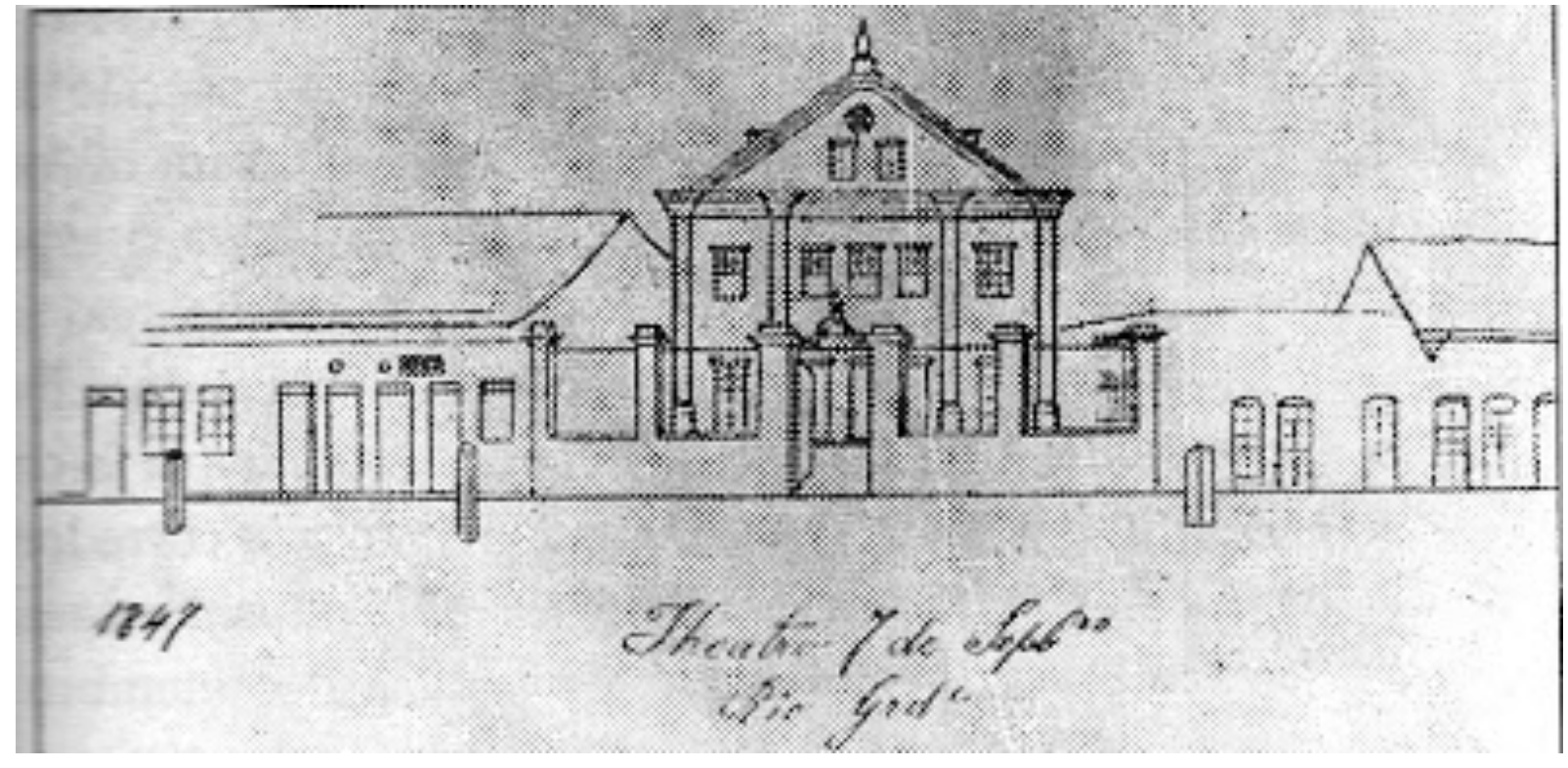

Fonte: Aspectos Brasileiros: meados do século XIX, Rio Grande: Biblioteca Rio-Grandense,1937.

Em 1851, a peça de Joana entrou para o repertório da companhia de João Caetano. A obra foi classificada como drama-vaudeville em 4 atos ${ }^{13}$. A direção do espetáculo foi do próprio ator, que o preparou pessoalmente, embora a companhia contasse com outro ensaiador. O papel de Jerônimo Morel coube ao segundo ator da companhia, Joaquim Augusto Ribeiro, tendo também tomado parte no elenco Estela Sezefreda (atriz, esposa de João Caetano) e Gabriela da Cunha De Vecchi, jovem estrela da companhia.

Os comentários na imprensa foram bons. "É esse segundo ato um belo espelho de moral! Ele arrancou-nos lágrimas, e muito nos comoveu - é a pintura

12 Tradução do drama em 5 atos, Jacques, le corsaire, de Ch. Desnoyer e Nus-Follet, compositor original não identificado, estreado no Théâtre de la Gaité em 1844. A peça estreou na corte em outubro de 1846, quando o casal Noronha já tinha partido para os Estados Unidos, mas o texto pode ter sido terminado antes dessa data.

${ }^{13}$ A nomenclatura dos gêneros teatrais nem sempre é rigorosa e pode ter seu significado alterado ao longo do tempo. O termo "vaudeville", hoje, descreveria uma obra cômica, mas a expressão "drama-vaudeville", em meados do século XIX indicava que se tratava de um drama com música. 
de muitos casos na sociedade" (D. M., Diário do Rio de Janeiro, 22 de julho de 1851, p.2). O crítico referia-se à figura do chefe da família Morel, alquebrado pelo peso da miséria, mas ainda assim lutando por sua honra. No terceiro ato o vilão é desmascarado e no quarto, punido.

Apesar dos elogios, os críticos não deixaram de anotar algumas falhas, como o abuso de palavras indecentes, o que seria um pouco de realismo demais para a cena. Porém, o comentário mais consequente é aquele que aponta que o desenvolvimento da trama traz desdobramentos que não se devem ao que é visto em cena, especificamente, mas àquilo que se conhece do romance. Desse modo, se por um lado evitam-se os temas mais chocantes, como o episódio do infanticídio (que posto no palco poderia ter um impacto maior do que na folha de papel do romance), por outro, a punição "exemplar" do vilão torna-se excessiva se considerado o que "realmente" se viu acontecer na peça.

Vale lembrar que Joana, na apresentação do romance, declarou:

Al poner a esta obra el título de "MISTERIOS DEL PLATA: romance histórico contemporáneo"; no es mi ánimo imitar los Misterios de Paris de Eugenio Sué; ni hacer otros Misterios de Londres. [...]. Misterios negros como el abismo, casi increibles en esta época y que es necesario que aparezcan a la luz de la verdad para que el crimen no pueda llevar por mais tiempo la máscara de la virtud (Noronha, J. 1852,...https://biblioteca.org.ar/libros/71176.pdf , p.1).

Se a obra de Sue desvendava as injustiças sociais da sociedade parisiense, misturadas, melodramaticamente, às desventuras do herói, o príncipe Rodolfo, o romance de Joana tem caráter de forte denúncia política, uma obra que se reporta, ainda que mude alguns nomes de personagens, a fatos históricos recentes. Evidentemente, a própria trajetória de vida de Joana forneceu o material necessário à composição do romance. E, ainda que os acontecimentos se sustentem sobre um protagonista masculino, Joana procurou destacar uma personagem feminina, Antonia Ansina, mulher do dissidente Dr. Valentin Ansina, de quem salva a vida em várias ocasiões por força de sua coragem e persistência. Da mesma forma, A família Morel valoriza as peripécias de Luiza, filha do sr. Morel, que enfrenta a vilania e a luxúria de seu patrão, Jacques Ferrand, sempre no intuito 
de proteger sua pobre família. Os atos do drama foram nomeados como: $A$ virtude e a hipocrisia, A miséria e a loucura, O ópio e o castigo e A felicidade e o amor recompensado.

Da encenação de 1851, outros aspectos do espetáculo foram considerados medianos. A adequação e o desempenho dos atores agradou a alguns e a outros não. A única unanimidade foi a música de Francisco de Sá Noronha, avaliada como bastante boa.

O que despertou a atenção dos comentaristas foi o fato de tratar-se de uma autora. Nesse caso, não se poderia fazer uma crítica mais dura por tratar-se "de uma senhora" (Diário Mercantil,19 de julho de 1851, p.2).

Contudo, o fato de ser uma mulher a autora não prejudicou a negociação sobre os direitos autorais de Joana. Ainda que a peça não fosse um estrondoso sucesso sabe-se que ela recebeu $500 \$$ (quinhentos mil réis) pelo texto ${ }^{14}$ de $A$ família Morel, quantia bastante significativa, e o mesmo valor para seu trabalho seguinte, o drama, composto a partir dos personagens do romance Notre Dame de Paris, de Victor Hugo, chamado Esmeralda. Os comentários da imprensa deram mais destaque à música de Francisco do que, propriamente, à peça. Esta foi vista como desprovida de sentimentos, com personagens frios e distantes, o que seria de se estranhar, uma vez que fora escrito por uma dama. Novamente, o inusitado de uma composição feminina e que, ainda por cima, não se enquadrava no modelo cultural vigente que via na mulher um poço de sentimentalismo sem fim. "É para admirar que um drama; produção de uma dama, seja tão escasso de paixões, quando o coração da mulher é o cofre delas, sobretudo do amor?" ( O Martinho, 27 de julho de 1851, p. 3).

O espetáculo estreou em 23 de julho de 1851, em comemoração ao aniversário da aclamação de D. Pedro II, com a presença do casal imperial, em grande gala, com hino nacional e discursos como acontecia nessas ocasiões. A etiqueta nessas situações previa a ausência de manifestações do público. Ele não deveria nem

${ }^{14}$ Os direitos autorais pagos durante o século XIX seguiam um sistema diferente dos de hoje. Em geral, o autor "vendia" sua peça à companhia dramática e tinha direito ao recebimento da arrecadação de uma récita. Não havia pagamento para autores de textos traduzidos (apenas um valor fixo para o tradutor) ou de textos já publicados. A situação, no teatro, só veio a mudar com a criação da Sociedade Brasileira de Autores Teatrais (SBAT) em 1917. 
mesmo aplaudir! Mas, segundo consta, "o sucesso foi grande e a plateia aplaudiu com entusiasmo, apesar de nisto se transgredirem as regras e estilos guardados nos dias de gala, em que o público perde ou the fica suspenso o exercício [...] de aplaudir ou patear" (Correio Mercantil, 25 de julho de 1851, p.1).

O elenco foi encabeçado por Gabriela da Cunha De Vecchi, que se destacava cada vez mais como a melhor atriz de sua geração, enquanto a grande estrela da companhia, a portuguesa Ludovina Soares da Costa, atuou como Gudula, a louca. Quasimodo foi interpretado pelo experiente ator, também português, José Areas. A música de Sá Noronha compreendia coros e "peças de músicas", ensaiadas por ele próprio. A obra foi tipificada também como vaudeville.

Depois de julho de 1851, as notícias sobre Joana desaparecem dos periódicos até novembro desse mesmo ano, quando se registra que ela chegou do Rio Grande do Sul com as duas filhas. Francisco não é mencionado entre os passageiros ${ }^{15}$.

Em 1852, além de tratar da fundação do Jornal das Senhoras, escreveu outro drama, em 4 atos, com música de Francisco, A saloia ${ }^{16}$, também apresentado pela companhia do São Pedro. A obra foi classificada como ópera ou melodrama. Ainda que o texto esteja perdido até o momento, sabe-se pelos anúncios que há um Barão de Santo Amaro (português?), um Sir Arthur Haverly (inglês?) e que o enredo tem diferença de dez anos entre o primeiro e os dois últimos atos. O papel principal foi dado à jovem e novata atriz Rosina Augusta de Souza (irmã do ator Joaquim Augusto). A estreia se deu em 13 de maio de 1852. As críticas cariocas são escassas, mas em 1853, Joana estava em Recife e A saloia foi encenada no Teatro Santa Isabel, tendo como protagonista Gabriela da Cunha De Vecchi, que recebeu muitos elogios por sua interpretação ${ }^{17}$, pois soube valorizar a variedade de emoções apresentadas pela obra, que oscilava entre o cômico e o dramático. Uma pequena nota nessa ocasião, traz mais uma informação sobre o enredo: "[...] Maria, pobre filha ilegítima da nobre e perversa marquesa de Vila Nova com o estudante

${ }^{15}$ Não foi possível identificar as atividades da autora no Rio Grande do Sul ou fora do país nesse período.

${ }^{16}$ Em Portugal, a palavra significa camponesa, podendo também designar uma pessoa rústica, grosseira ou desonesta.

${ }^{17}$ Gabriela da Cunha havia se desentendido com João Caetano e saído da companhia do Teatro de São Pedro de Alcântara. 
Pedro Paulo" (Diário de Pernambuco, 12 de dezembro de 1853, p. 1). Note-se também a curiosa caracterização feita de Joana, apresentada como escritora americana. Parece que ficava difícil classificar uma escritora argentina, vivendo no Brasil e escrevendo sobre um tema português.

A obra seguinte de Joana também abandona as referências e o esteio de personagens e tramas já conhecidas do público para abordar um assunto da atualidade, político e fundamental na vida da autora. No fim de 1852, ela já tem pronto o drama Três dias de um mês de Rosas. Este é o primeiro título da peça que viria a se chamar O ditador Rosas e a Mashorca, drama em 6 quadros e epílogo, sobre as atrocidades perpetradas pelo regime argentino e a vitória das forças brasileiras sobre o general Rosas ${ }^{18}$. Foi escrito como comemoração à derrubada do regime que a tinha expulsado de sua terra natal.

Mas entre o fim do conflito e a estreia do espetáculo, muito foi debatido sobre a conveniência do texto ser encenado. Há dois processos no Conservatório sobre a peça. Inicialmente, com o primeiro título: Três dias do mês de Rosas (BN - CDB, 1-08,10,01919), de maio de 1853. Dele constam manifestações enviadas pelo ensaiador da companhia, Emílio Doux, pelo empresário, João Caetano, por dois pareceristas, Luiz Vicente De Simoni e Tomás José Pinto Cerqueira e pela própria autora. Contatos vinham se dando desde o início de agosto de 1852, quando De Simoni foi indicado para fazer o parecer. Sua avaliação é longa e logo a princípio se coloca contra a encenação do texto. Seus argumentos são de natureza política, aspecto pouco comum nos pareceres que, em geral, reprovavam peças por questões morais. Pareceu-lhe, em resumo, que o momento era impróprio e que seria um ato impolítico, comprometendo a posição do governo brasileiro. O lapso de tempo entre os acontecimentos e a peça ainda seria muito pequeno. Para uma peça ser considerada histórica, achava que deveria decorrer pelo menos meio

\footnotetext{
18 Rosas, alçado ao poder em 1830, tentava restabelecer o grande Vice-Reino do Prata, que incorporava Paraguai, Bolívia e Uruguai, além da própria Argentina. O caudilho manteve-se em conflito com esses Estados e também com as grandes potências da época. França e Inglaterra. O Brasil acabou se envolvendo diretamente em 1851, no que ficou conhecido na nossa história como Guerra do Prata ou Guerra contra Oribe e Rosas, apoiando sobretudo o Uruguai, liderado pelo general uruguaio Urquiza. Joana voltou ao assunto da história argentina em um longo texto publicado pelo Diário do Rio de Janeiro entre outubro e novembro de 1858, pouco tempo antes de deixar o Brasil sobre a história das Guerras do Prata, que intitulou Páginas da Mocidade: Memórias das Guerras Civis no Rio da Prata (1838-1841).

http://objdigital.bn.br/objdigital2/acervo_digital/div_manuscritos/mss1448256/mss1448256.pdf
} 
século ou duas gerações entre o fato e a obra. Colocando-se próximo do ocorrido, os episódios apresentados não serviam como exemplo e ensino, mas apenas como um ataque a um personagem ainda vivo ${ }^{20}$. Para corroborar sua posição chega a invocar até Platão.

Do ponto de vista do trabalho dramatúrgico, anota o ineditismo de ter sido escrito por uma mulher, o que aguçara sua curiosidade. Ainda que reprove o partido tomado por ela de ignorar as regras clássicas das unidades (lembrando que ele era um famosos latinista) e também aponte vários erros ortográficos e de gramática, que supõe possam ter ocorrido por culpa dos copistas, destaca a "beleza de estilo e de ação dramática", com "situações e golpes de cena interessantes”, bem como "diálogos animados”. Ainda assim, proíbe a encenação, recomendando que ela se desse "em circunstâncias menos impróprias".

Como estava estabelecido nos estatutos do Conservatório, no caso de proibição o texto era enviado a um segundo parecerista. Então, em agosto de 1852, ele chegou às mãos de Tomás José Pinto Cerqueira, que se pronunciou favorável à montagem. Cerqueira destacou também o fato de ele ter sido escrito por uma autora, o que viu com muito bons olhos, comparando a situação brasileira com a de países como França e Inglaterra, onde as mulheres se dedicavam mais frequentemente às letras. Menciona também o teatro clássico (Corneille e Racine) como modelo de qualidade dramática. Seu parecer é favorável à encenação e chega até a ser um entusiasta. "Avante! Avante!" é como termina seu texto.

Diante do empate na avaliação, o presidente do Conservatório, Diogo Soares da Silva de Bivar, como the cabia nessas situações, decidiu e proibiu a encenação.

Joana, certamente, foi comunicada da decisão e, ao que tudo indica, conforme o documento datado de 7 de março de 1853, que integra o dossiê, fez um acordo com o Conservatório. Na carta, menciona uma promessa do presidente Bivar de três meses antes, isto é, de dezembro de 1852, de que a peça poderia ir à cena em breve. Joana dava sua palavra que o espetáculo só estrearia em maio de 1853, mas que era preciso aprová-lo desde então para que se pudesse dar início aos ensaios. Assim, em 25 de abril, o Conservatório comunicou o chefe da polícia

20 Lembremos também que o capítulo final de Os Mistérios do Prata não pôde ser publicado, como Joana explica, sem no entanto revelar o motivo. Provavelmente, pelo mesmo problema que enfrentou seu drama. 
de que o drama tinha sido liberado.

Ainda assim, algum problema ocorreu no fim de maio, quando o espetáculo começou a ser anunciado nos jornais. Entre 21 e 27 desse mês, diversas mensagens foram enviadas ao Conservatório. O diretor da companhia, João Caetano, queixou-se de boatos de que a peça seria proibida. Três dias depois, Joana voltou a dirigir-se a Bivar, explicando que havia trocado o título da obra para o ditador Rosas e a Mashorca, mas que se tratava do mesmo drama anteriormente apresentado, e que sua intenção tinha sido apenas deixar mais claro para o público o assunto da peça. Por fim, o ensaiador, Emílio Doux, também pediu permissão para continuar com os ensaios, enquanto se resolvia em definitivo a questão da aprovação.

O ditador Rosas e a Mashorca estreou em 7 de junho de 1853, com os seis quadros denominados como: O noivado, O último adeus!, Rosas e Coutinho, $A$ pobre mãe, O botequim da Federação, A mulher de Agostinho e o epílogo, Três anos depois. A interpretação do General Rosas coube também a Joaquim Augusto Ribeiro e o principal papel feminino a Ludovina Soares da Costa, a grande dama do teatro nacional da época. A encenação pediu também grande número de figurantes: soldados, serenos²1, oficiais, povo e "mashorqueiros". O epílogo era uma grande apoteose, cheia de efeitos cênicos e de "sublimes inspirações", segundo o Jornal do Comércio (6 de junho de 1853, p. 2).

A última peça brasileira ${ }^{22}$ escrita por Joana foi a comédia-vaudeville em dois atos As manias do século ou os rapazes de agora ${ }^{23}$. As manias satirizadas eram o ultra-romantismo, o jornalismo, o magnetismo e os vapores. É fácil entender o sentido dos termos ultra-romantismo e jornalismo. Os outros dois são mais datados. O magnetismo se referia a uma onda de aplicações às mais diversas situações os campos magnéticos que tinham sido recentemente descobertos pelos cientistas e passavam a ser manipuláveis pelos dispositivos

${ }^{21}$ Nome dado aos guardas-noturnos que faziam o policiamento da cidade [Montevidéu], trazendo à mão uma lanterna e apregoando as horas (Diário do Rio de Janeiro, 9 ago. 1851, p.1).

\footnotetext{
22 Ela ainda viria a escrever uma última peça na Argentina em 1864: La revolución de Mayo: 1810.

${ }^{23}$ Não encontramos informação sobre a autoria das músicas, mas supomos que elas devam ter sido de autoria de Francisco Noronha.
} 
eletromagnéticos. As forças dos ímãs passaram a ser aplicadas a quase tudo. Inclusive aos indivíduos pelo "magnetismo animal". Já vapores se referia às características psicológicas de indivíduos com tendências à melancolia, depressão etc. ${ }^{24}$

Não foi encontrada nenhuma crítica na imprensa, mas existe um parecer censório. Vale destacar que o pedido de liberação foi feito pela própria autora, o que era bastante incomum nos processos do Conservatório. Houve muito menos polêmica sobre esta pequena comédia, cujo título original era Os rapazes d’agora ou as manias do século, do que sobre o drama Rosas. Mesmo assim, foi necessário enviá-la a um segundo censor, Luiz Honório Vieira Souto, que concordou com o primeiro, Luiz Fortunato de Brito, sobre a troca de algumas palavras, e chamou a obra de farsa. A peça foi encenada em um benefício em favor de Joana, que contou com a presença do casal imperial, portanto, sinal de grande prestígio para a autora.

Periódico dos Pobres

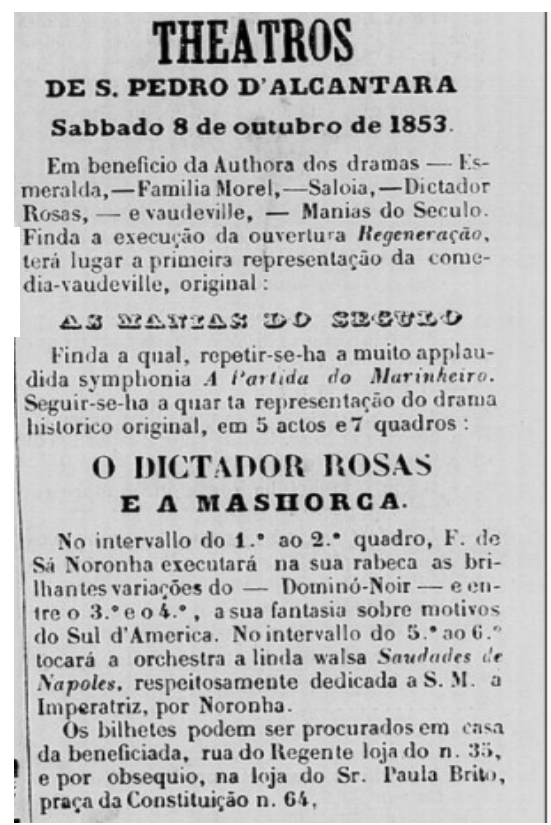

Rio de Janeiro, 6 de outubro de 1853, ano IV, n. 110, p.4

${ }^{24}$ Segundo Vagner Camilo (2001), p. 158-159: [Ross] Chambers fala, a princípio de uma ‘epidemia de tédio’ denunciada por Baudelaire em Au lecteur e por Ema Bovary em seu exílio normando -, visto menos como uma forma de oposição e mais como um produto direto da regularidade e uniformização da vida imposta pela ordem burguesa. [...]. Pois a palavra spleen, denunciando o carácter inglês (portanto moderno) do mal, permite, remetendo à antiga medicina dos humores, aprofundar as características do 'novo' vago n'alma. Etimologicamente aparentada à cólera (do grego kholé, baço), a melancolia é também 'cólera vaporizada', diagnosticada à época como produto dos vapores provenientes do baço, sede do 'humor negro', que ameaçava a 'sede da razão e da ... ordem' e provocava a vertigens, náuseas, desmaios e fraquezas (o que se resumia na expressão 'ter vapores'). Nos casos extremos, levava ao que hoje denominamos de angústia ou depressão [...]. 
Logo depois da encenação de As manias do século, Joana e Francisco se separaram e cada qual tomou um rumo diferente. Francisco embarcou para a Europa, acompanhado por outra mulher, e Joana voltou com as filhas para Buenos Aires. Encontram-se comentários discretos e alusões indiretas de Joana sobre essa situação. Na verdade, tratou-se de um escândalo para a época. Tempos depois, Joana viria a publicar um texto chamado Consolações (dedicado à sua amiga, a atriz Gabriela da Cunha de Vecchy) no qual lamenta sua separação. Nesse momento, Joana já havia voltado à corte e dado início a uma segunda etapa de sua carreira no teatro brasileiro, não mais como dramaturga (embora suas peças continuassem a ser representadas esporadicamente), mas como atriz. Segundo seu próprio depoimento, essa foi a única forma que encontrou de prover o sustento de suas filhas, "assim como o dever de educá-las e amparar a velhice de minha mãe, viúva" (Diário do Rio de Janeiro, 4 de setembro de 1858, p. 2). Em junho de 1855, ela estreou como parte do elenco da nova companhia do Teatro Ginásio Dramático, criada pela atriz Maria Velluti, pelo empresário Joaquim Heleodoro dos Santos e pelo ensaiador francês radicado no Brasil, Emílio Doux.

Como se sabe, o grupo do Ginásio Dramático procurou renovar o repertório do teatro brasileiro apresentando os novos dramas realistas franceses que vinham surgindo desde a montagem de A Dama das Camélias, de Alexandre Dumas Filho, em 1852 em Paris. Numa primeira fase, o Ginásio traduziu e apresentou peças de Émile Augier, Theodore Barrière e do próprio Dumas Filho.

Apesar de manter ainda um sotaque portenho, a estreia de Joana na peça $A$ atriz, o teatro e os doidos, de Clairville e Holstein, recebeu o apoio de Machado de Assis em sua crítica ao espetáculo ${ }^{25}$. Joana participou também dos grandes sucessos do realismo francês encenados pelo Ginásio, como A Dama das Camélias ${ }^{26}$.

O talento de Joana foi reconhecido também pelo ensaiador da companhia, E. Doux, que, ao deixar o grupo e voltar para a companhia do Teatro São Pedro (na qual atuou desde 1852) levou a atriz consigo. Na nova trupe, Joana voltou a

${ }^{25}$ Correio Mercantil, 22 de julho de 1855, p.1.

${ }^{26}$ Ver lista de espetáculos no fim do artigo. 
colaborar com João Caetano, mas agora como parceira de palco. Lá também reencontrou Francisco e voltou a trabalhar com ele, embora não haja sinais de que tenham voltado a viver juntos. Porém, em 1857, Joana desentendeu-se com Caetano por causa de direitos de benefícios e retornou ao Ginásio.

Nessa última fase de sua permanência no Brasil, suas filhas passaram a apresentar-se também em cena, como era bastante comum na época, quando os artistas do palco formavam-se no trabalho desde cedo junto a seus familiares.

As peças que o Ginásio encenava por essa época não eram mais só as traduções francesas, mas originais brasileiros de novos autores que se dedicaram ao gênero, a começar por José de Alencar. Ela participou das montagens de Rio de Janeiro, verso e reverso; O demônio familiar, As asas de um anjo e O crédito. Sobre As asas de um anjo disse a crítica: "Cabem as honras da noite às senhoras Adelaide, Clotilde e Noronha", acrescentando a descrição de um episódio curioso: "O cenário esteve completo, notando-se porém que as cadeiras que apareceram no penúltimo ato ou na casa da pobre Carolina, eram tão velhas que a sra. Noronha, a não ter the valido a cama que estava perto da cadeira em que ia sentarse, teria ido ao chão" (Correio Mercantil, 10 de junho de 1858, p.2).

Joana tomou parte também da primeira experiência, ainda que não muito bem sucedida, da encenação de nossa primeira revista de ano, As surpresas do sr. José da Piedade, montada pelo Ginásio.

Em geral, as críticas à sua atuação eram boas, ainda que nem sempre entusiasmadas. Parece ter sido uma atriz "correta”. Joana permaneceu no Ginásio até sua volta definitiva para a Argentina no início de 1859.

Em seu país natal desenvolveu intenso e importante trabalho na área da educação, chegando a ser assessora bastante próxima do presidente Domingo F. Sarmiento (1868-1874), político que sempre atuou em prol da educação pública. Joana faleceu em Buenos Aires em 1875.

Na história do teatro brasileiro o nome de Joana Paula Manso de Noronha é praticamente desconhecido ${ }^{27}$. Contudo, a pesquisa sobre essa figura, nos levou a

${ }^{27}$ Embora seja bastante conhecido entre os pesquisadores da história do jornalismo, da educação ou dos estudos feministas. 
encontrar aquela que pode ser considerada a primeira dramaturga brasileira de relevância, apesar de estrangeira. Sua produção esteve envolvida e foi condicionada pela realidade teatral do Rio de Janeiro de meados dos anos de 1840 e 1850. O teatro foi para ela, segundo suas próprias palavras, uma "tábua de salvação" (Diário do Rio de Janeiro, 4 de setembro de 1858, p.2). Ela teve que desenvolver-se como autora a partir das condições reais que encontrou na corte e nas províncias. Em suas memórias de juventude, Joana menciona o teatro apenas uma vez, para dizer qual era sua formação, em 1840, que avalia como pequena. Portanto, o que ela realizou no teatro, o fez a partir de uma vivência brasileira.

Minha instrução literária não ia além do conhecimento do teatro antigo e moderno espanhol: conhecia Racine e Molière, Walter Scott e Richardson, alemão Campfe e Ana Radchiffe, Bernardin de Saint Pierre e Staël, Mme Cottin e [ - ] Cooper, Balzac, Hugo, Lamartine, Dumas, George Sand, Espronceda. [...]. Minha primeira estação de dois anos no Rio de Janeiro foi empregada em constantes leituras, que deram novas latitudes às ideias, outra têmpera mais forte à alma (Diário do Rio de Janeiro, 19 nov. 1858, p.3).

Os nomes de outras autoras ${ }^{28}$ de que temos conhecimento apareceram tempos depois de Joana ter escrito e encenado suas peças. Como tradutora e autora sua carreira começou já na década de 1840. Seus textos inicialmente apoiam-se em enredos já conhecidos a partir de romances de grande sucesso, ou mesmo de peças compostas a partir deles. A autora se enquadra nessa prática tão comum do século XIX e faz as suas próprias adaptações. Mas escreveu também obras originais, ainda bem distintas uma da outra, procurando sempre que possível colocar em cena uma heroína ${ }^{29}$.

Vale destacar sua parceria artística com Francisco de Sá Noronha, longa e fecunda, que revela o peso que a composição musical para o teatro tinha na economia da cena, aspecto nem sempre considerado nos estudos desse período.

Ao nos interessarmos em conhecer melhor essa Sra. tão envolvida na companhia do Teatro de São Pedro de Alcântara e no Ginásio, não foi sem surpresa

\footnotetext{
${ }^{28}$ A atriz portuguesa Gertrudes da Cunha (mãe da atriz Gabriela da Cunha) ou Maria Velluti, por exemplo.

29 Das obras citadas apenas é conhecido o paradeiro de A família Morel, mencionada em nota de rodapé por Décio de Almeida Prado (1972, p. 86)
} 
que identificamos nela a figura tão excepcional de Joana de Paula Manso de Noronha. Portanto, foi na intenção de contribuir para o melhor conhecimento de sua biografia e para que se possa começar a fazer uma apreciação sobre sua contribuição ao teatro no Brasil que nos propusemos a apresentar este relato, ainda que inicial, mas que, com certeza preenche uma lacuna importante na trajetória de uma personalidade singular e ilumina aspectos pouco conhecidos da cena nacional.

Esa imagen inolvidable es la tuya, mi bello Rio de Janeiro, princesa de los valles!

No volveré a verte, pero he cantado tu belleza y dejándote algo de mi misma como el solo recuerdo de mi peregrinación sobre tu suelo. [J. P. M. N.]

Tabela com os espetáculos nos quais Joana Manso de Noronha participou como atriz

\begin{tabular}{|c|c|c|c|c|}
\hline DATA & TÍTULO & $\begin{array}{l}\text { GÊNERO, } \\
\text { ATOS }\end{array}$ & PERSONAGEM & $\begin{array}{l}\text { AUTOR/ } \\
\text { TRADUTOR }\end{array}$ \\
\hline $15-7-1855$ & $\begin{array}{l}\text { A atriz, o teatro } \\
\text { e os doidos }\end{array}$ & C,3 & $\begin{array}{l}\text { Rosa/Rosine } \\
\text { Mulher de Galouzot e } \\
\text { mãe de Colomba }\end{array}$ & Clairville e Hostein / Maria Velluti \\
\hline $29-7-1855$ & $\begin{array}{l}\text { O amigo } \\
\text { Grandet }\end{array}$ & C, 3 & $\begin{array}{l}\text { Princesa Blamont- } \\
\text { Chouvry }\end{array}$ & $\begin{array}{c}\text { Ancelot e Alexis de Comberousse / } \\
\text { João Batista Ferreira }\end{array}$ \\
\hline $11-8-1855$ & $\begin{array}{l}\text { Um homem } \\
\text { atrás das } \\
\text { mulheres }\end{array}$ & $C, 2$ & Evalina & Th. Barrière e A. Decoucelle / Amoêdo \\
\hline $28-8-1855$ & $\begin{array}{l}\text { Rapaz moço e } \\
\text { mulher velha }\end{array}$ & $\mathrm{C}, 4$ & Mme de Beaufort & $\begin{array}{c}\text { Édouard-Joseph-Ennemond Mazères } \\
\text { / Carlota Talassi }\end{array}$ \\
\hline $28-8-1855$ & Tia Bazú & C,2 & $\begin{array}{c}\text { Mme Bernarda / Mme } \\
\text { Bernarda }\end{array}$ & M. Lardonois \\
\hline nov. 1855 & $\begin{array}{l}\text { Mulheres de } \\
\text { mármore }\end{array}$ & $\mathrm{D}, 5$ & $\begin{array}{l}\text { Sra. Didier / Mme. } \\
\text { Didier }\end{array}$ & $\begin{array}{c}\text { Theodore Barrière e L. Thiboust / José } \\
\text { Joaquim Vieira Souto }\end{array}$ \\
\hline nov.1855 & As três leoas & $\mathrm{C}, 2$ & Aspasia / Saint-Fleur & Bayard e Dumanoir / Maria Velluti \\
\hline nov. 1855 & $\begin{array}{l}\text { A vendedora de } \\
\text { perus }\end{array}$ & $\begin{array}{l}\text { C,2 } \\
\text { com } \\
\text { música }\end{array}$ & $\begin{array}{l}\text { Baronesa Peternick / } \\
\text { La Barone }\end{array}$ & $\begin{array}{l}\text { A Dartois, Bièville e Dejazet / Maria } \\
\text { Velluti }\end{array}$ \\
\hline
\end{tabular}




\begin{tabular}{|c|c|c|c|c|}
\hline DATA & TÍTULO & $\begin{array}{l}\text { GÊNERO, } \\
\text { ATOS }\end{array}$ & PERSONAGEM & $\begin{array}{l}\text { AUTOR/ } \\
\text { TRADUTOR }\end{array}$ \\
\hline $1-1-1856$ & $\begin{array}{l}\text { Um rei feito à } \\
\text { força }\end{array}$ & $\mathrm{C}, 2$ & $\begin{array}{c}\text { Baronesa } \\
\text { Kerbeck/Barone } \\
\text { Kelbeck }\end{array}$ & $\begin{array}{c}\text { Montjoye e Joutard / José Joaquim } \\
\text { Vieira Souto }\end{array}$ \\
\hline $13-1-1856$ & $\begin{array}{l}\text { O sargento } \\
\text { Frederico }\end{array}$ & $\begin{array}{l}\text { D,5 } \\
\text { ornado de } \\
\text { música }\end{array}$ & $\begin{array}{l}\text { Rainha Sofia / } \\
\text { Reine Sophie }\end{array}$ & Émile Vanderburch \\
\hline $7-2-1856$ & $\begin{array}{l}\text { A Dama das } \\
\text { Camélias }\end{array}$ & $\mathrm{D}, 5$ & $\begin{array}{l}\text { Prudência Duvernoy / } \\
\text { Prudence }\end{array}$ & $\begin{array}{c}\text { Dumas Filho / José Joaquim Vieira } \\
\text { Souto }\end{array}$ \\
\hline $8-4-1856$ & $\begin{array}{l}\text { Os três } \\
\text { pontapés }\end{array}$ & $\mathrm{C}, 2$ & A. Margrave & Alexis de Comberousse e M. Lockroy \\
\hline $22-4-1856$ & $\begin{array}{l}\text { Um velho da } \\
\text { têmpera antiga }\end{array}$ & $\mathrm{C}, 1$ & $\begin{array}{l}\text { Julieta (criada) / } \\
\text { Juliette (femme de } \\
\text { chambre - } 24 \text { ans) }\end{array}$ & $\begin{array}{c}\text { Dupety e E. Grangé / José Joaquim } \\
\text { Vieira Souto }\end{array}$ \\
\hline $24-4-1856$ & $\begin{array}{l}\text { médico das } \\
\text { crianças }\end{array}$ & $\mathrm{D}, 5$ & $\begin{array}{l}\text { Antonia / Toinette } \\
\text { (soubrette) }\end{array}$ & $\begin{array}{c}\text { Anicet-Bourgeoir e Adolphe Dennery / } \\
\text { José Joaquim Vieira Souto }\end{array}$ \\
\hline $24-4-1856$ & Na rua da lua & $\mathrm{C}, 1$ & $\begin{array}{l}\text { Eglantina / Mme. } \\
\text { Chaudeorelle }\end{array}$ & $\begin{array}{c}\text { Varin e Boyer / José Joaquim Vieira } \\
\text { Souto }\end{array}$ \\
\hline $17-5-1856$ & $\begin{array}{l}\text { o casamento a } \\
\text { marche-marche }\end{array}$ & $C, 1$ & $?$ & De Leuven e Brunswich \\
\hline $17-5-1856$ & $\begin{array}{l}\text { A noiva de } 64 \\
\text { anos }\end{array}$ & $\mathrm{C}, 3$ & $\begin{array}{l}\text { Mariquinhas (velha aia } \\
\text { da família ) / Marcuccia }\end{array}$ & Francesco Augusto Bom / Maria Velluti \\
\hline $17-5-1856$ & $\begin{array}{l}\text { O celibatário e } \\
\text { a menina }\end{array}$ & $\mathrm{C}, 1$ & $?$ & E. Scribe e Delavigne \\
\hline $1-6-1856$ & $\begin{array}{l}\text { A filha de } \\
\text { Jacquelina }\end{array}$ & $\mathrm{C}, 2$ & $\begin{array}{l}\text { Marquesa de } \\
\text { Rochegyon / La } \\
\text { marquise }\end{array}$ & Dumanoir e Édouard Brisebarre \\
\hline $17-6-1856$ & $\begin{array}{l}\text { A alegria da } \\
\text { casa }\end{array}$ & C, 3 & $\begin{array}{l}\text { Sra. de Baront / Mme } \\
\text { de Baront }\end{array}$ & $\begin{array}{c}\text { Anicet Bourgeois e Decourcelle / } \\
\text { Duque Estrada }\end{array}$ \\
\hline $20-7-1856$ & $\begin{array}{l}\text { Viscondessa } \\
\text { Lolota }\end{array}$ & $\mathrm{C}, 3$ & Marquesa d'Herouville & Bayard e Dumanoir / Dr. Sampaio \\
\hline $20-7-1856$ & A gargalhada & $D, 5$ & $\begin{array}{c}\text { Mme. Lagrange (mão } \\
\text { do protagonista) / } \\
\text { Mme. Lagrange }\end{array}$ & Jacques Arago e Martin \\
\hline $9-9-1856$ & $\begin{array}{l}\text { A torre de } \\
\text { Londres }\end{array}$ & $\mathrm{D}, 5$ & $\begin{array}{l}\text { Clay Murray, Cond. de } \\
\text { Carlile }\end{array}$ & $\begin{array}{l}\text { Eugene Nus, Alphonse Brot e Charles } \\
\text { Lemaitre / José Joaquim Vieira Souto }\end{array}$ \\
\hline $24-8-1856$ & $\begin{array}{c}\text { A heredipeta } \\
\text { lograda }\end{array}$ & $\mathrm{C}, 2$ & Raqueta (criada) & $?$ \\
\hline
\end{tabular}




\begin{tabular}{|c|c|c|c|c|}
\hline DATA & TÍTULO & $\begin{array}{l}\text { GÊNERO, } \\
\text { ATOS }\end{array}$ & PERSONAGEM & $\begin{array}{l}\text { AUTOR/ } \\
\text { TRADUTOR }\end{array}$ \\
\hline $31-8-1856$ & $\begin{array}{l}\text { Fouquet ou o } \\
\text { torreão de } \\
\text { Vincennes }\end{array}$ & $\mathrm{D}, 5+7 \mathrm{Q}$ & $\begin{array}{l}\text { Ana d'Austria / } \\
\text { Anne d'Autriche }\end{array}$ & Dennery e Grangé / Dr. Sampaio \\
\hline $21-9-1856$ & A nova Castro & $\mathrm{T}, 5$ & Elvira & João Batista Gomes Júnior \\
\hline $25-9-1856$ & $\begin{array}{l}\text { A fritada } \\
\text { fantástica }\end{array}$ & $\mathrm{C}, 1$ & ? & $\begin{array}{c}\text { Boyer Partout e Duvert / } \\
?\end{array}$ \\
\hline $25-9-1856$ & O noviço & $C, 3$ & ? & Martins Pena \\
\hline $9-10-1856$ & $\begin{array}{l}\text { O vigário de } \\
\text { Wakefield }\end{array}$ & $\mathrm{D}, 5$ & ? & $\begin{array}{c}\text { Eugene Nus e Tisserant / José } \\
\text { Joaquim Vieira Souto }\end{array}$ \\
\hline $12-10-1856$ & $\begin{array}{c}\text { Os sete infantes } \\
\text { de Lara }\end{array}$ & $D, 5$ & $?$ & Felicien Mallefille / ? \\
\hline $26-10-1856$ & $\begin{array}{l}\text { Jenny a } \\
\text { bordadeira }\end{array}$ & $\mathrm{D}, 5$ & Bertha / Berthe & $\begin{array}{l}\text { A. Decourcelle, Jule Barbière / José } \\
\text { Joaquim Vieira Souto }\end{array}$ \\
\hline $26-10-1856$ & $\begin{array}{l}\text { O caçador de } \\
\text { leões }\end{array}$ & $\mathrm{C}, 1$ & Herminia / Hermine & $\begin{array}{c}\text { Lambert Thibourt [Thisbout] e E. } \\
\text { Lehmann }\end{array}$ \\
\hline $9-11-1856$ & Otelo & $\mathrm{T}, 5$ & Hermance (Ama) & Jean-François Ducis \\
\hline $28-12-1856$ & A graça de Deus & $\mathrm{D}, 5$ & $\begin{array}{l}\text { Madalena / } \\
\text { Madeleine Loustalot }\end{array}$ & D'Ennery e Gustave Lemoine / ? \\
\hline $23-1-1857$ & $\begin{array}{l}\text { O pai Gonçalo } \\
\text { ou a eleição de } \\
\text { um juiz de paz }\end{array}$ & $\mathrm{C}, 1$ & Zeferina / & $?$ \\
\hline $20-1-1857$ & O espião fidalgo & $\mathrm{D}, 5$ & $\begin{array}{l}\text { Maria (criada da } \\
\text { duquesa) }\end{array}$ & $\begin{array}{c}\text { Saint George e Theodore Anne /José J. } \\
\text { Vieira Souto }\end{array}$ \\
\hline $1-2-1857$ & $\begin{array}{l}\text { Veja mas não } \\
\text { toque }\end{array}$ & $\mathrm{C}, 3$ & $\begin{array}{l}\text { Griselda (açapata da } \\
\text { rainha) }\end{array}$ & Theophile Gautier e Bernardo Lopez / \\
\hline $7-3-1857$ & $\begin{array}{l}\text { O marquês de } \\
\text { Pombal ou o } \\
\text { terremoto de } \\
1755\end{array}$ & $\mathrm{D}, 3+7 \mathrm{Q}$ & Julia & José Luiz Baiardo \\
\hline $25-3-1857$ & $\begin{array}{c}\text { Maria de } \\
\text { Rudenz ou a } \\
\text { freira } \\
\text { sanguinária }\end{array}$ & $\mathrm{D}, 5+6 \mathrm{Q}$ & Tecla (cigana) & Anicet-Bourgeois e Julien de Mallian \\
\hline
\end{tabular}




\begin{tabular}{|c|c|c|c|c|}
\hline DATA & TÍTULO & $\begin{array}{l}\text { GÊNERO, } \\
\text { ATOS }\end{array}$ & PERSONAGEM & $\begin{array}{l}\text { AUTOR/ } \\
\text { TRADUTOR }\end{array}$ \\
\hline $14-4-1857$ & $\begin{array}{l}\text { Oh!, que apuros } \\
\text { ou o noivo em } \\
\text { mangas de } \\
\text { camisa }\end{array}$ & $\mathrm{C}, 1$ & $\begin{array}{l}\text { Sra. Deolinda (Viúva } \\
\text { rica) }\end{array}$ & $\begin{array}{c}\text { Eugène Labiche, Auguste Lefranc e } \\
\text { Eugène Nyon / José Díaz Tezanos } \\
\text { ou }\end{array}$ \\
\hline $26-4-1857$ & $\begin{array}{l}\text { Álvaro da } \\
\text { Cunha ou o } \\
\text { cavaleiro de } \\
\text { Alcácer Quibir }\end{array}$ & $\mathrm{D}, 5$ & Luiza (criada) & João Cruz da Ferreira \\
\hline $28-4-1857$ & $\begin{array}{l}\text { Um fogo de } \\
\text { chaminé }\end{array}$ & $\mathrm{C}, 1$ & ? & $\begin{array}{c}\text { Eugène Labiche e Arthur de Beauplan / } \\
\text { Dr. Sampaio }\end{array}$ \\
\hline $6-5-1857$ & $\begin{array}{l}\text { Gabriel e } \\
\text { Lusbel, ou os } \\
\text { milagres de } \\
\text { Santo Antonio }\end{array}$ & $\mathrm{D}, 3+4 \mathrm{Q}$ & ? & José Maria Braz Martins \\
\hline $19-5-1857$ & $\begin{array}{l}\text { Notabilidade do } \\
\text { lugar }\end{array}$ & $\mathrm{C}, 3$ & ? & Charles Narrey \\
\hline mai. 1857 & $\begin{array}{c}\text { Graças a Deus, } \\
\text { está posta a } \\
\text { mesa }\end{array}$ & $\mathrm{C}, 1$ & ? & Léon Gozlan / Francisco Luis Machado \\
\hline $19-6-1857$ & $\begin{array}{l}\text { As aves de } \\
\text { rapina }\end{array}$ & $\mathrm{D}, 5$ & $\begin{array}{c}\text { Duquesa de Guerande } \\
\text { / }\end{array}$ & Adolphe D'Ennery / Dr. Sampaio \\
\hline $24-6-1857$ & $\begin{array}{c}\text { Paris que chora } \\
\text { e Paris que ri }\end{array}$ & $\mathrm{D}, 5+8 \mathrm{Q}$ & ? & $\begin{array}{c}\text { Laurecin (Paul-Aimé Chapelle) e } \\
\text { Eugéne Cormon }\end{array}$ \\
\hline $25-7-1857$ & $\begin{array}{l}\text { Os fanfarrões } \\
\text { de vícios }\end{array}$ & C,3 & Mme. Francis & Dumanoir e De Biévilles \\
\hline $25-7-1857$ & $\begin{array}{l}\text { A filha bem } \\
\text { guardada }\end{array}$ & $\mathrm{C}, 1$ & $\begin{array}{c}\text { Baronesa da } \\
\text { Formigueira / Baronne } \\
\text { de Flasquemont }\end{array}$ & Eugéne Labiche e Marc Michel \\
\hline $8-8-1857$ & $\begin{array}{c}\text { Recordações da } \\
\text { mocidade }\end{array}$ & $\mathrm{C}, 4$ & ? & $\begin{array}{c}\text { Lambert Thibust e Alfred Delacourt } 8 \\
\text { Sr. Dr.*** }\end{array}$ \\
\hline $15-8-1857$ & $\begin{array}{l}\text { visconde de } \\
\text { Létorières }\end{array}$ & $\mathrm{C}, 3$ & [Verônica] / Véronique & Bayard e Dumanoir / Duque Estrada \\
\hline $20-8-1857$ & Chiquinha presa & $C, 1$ & $\begin{array}{l}\text { Dorotéa (professora } \\
\text { inglesa) }\end{array}$ & $?$ \\
\hline $23-8-1857$ & $\begin{array}{l}\text { O filho do sr. } \\
\text { Godard }\end{array}$ & $\mathrm{C}, 3$ & $\begin{array}{l}\text { Mariana Piment / } \\
\text { Marianne Piment }\end{array}$ & Anicet Bourgeois e Decourcelle \\
\hline $29-8-1857$ & $\begin{array}{l}\text { Um episódio do } \\
\text { reino de } \\
\text { Jacques I }\end{array} \mid$ & $\mathrm{C}, 3$ & $\begin{array}{l}\text { Miss Fleumming } \\
\text { (governanta) }\end{array}$ & Prosper, Dinaux e E. Sue \\
\hline
\end{tabular}




\begin{tabular}{|c|c|c|c|c|}
\hline DATA & TÍTULO & $\begin{array}{l}\text { GÊNERO,AT } \\
\text { OS }\end{array}$ & PERSONAGEM & $\begin{array}{l}\text { AUTOR/ } \\
\text { TRADUTOR }\end{array}$ \\
\hline $29-8-1857$ & $\begin{array}{l}\text { As primeiras } \\
\text { proezas de } \\
\text { Richelieu }\end{array}$ & $C, 2$ & Duquesa de Noailes & Bayard e Dumanoir \\
\hline $19-9-1857$ & $\begin{array}{c}\text { Uma viagem } \\
\text { por mar e terra }\end{array}$ & C,4 & Dona Brígida & $\begin{array}{c}\text { Isidro Gil y Baus [?] e Silvestre Collar y } \\
\text { Bueren [?]/ Francisco Palha }\end{array}$ \\
\hline $11-10-1857$ & $\begin{array}{l}\text { O Tio André que } \\
\text { vem do Brasil }\end{array}$ & C,3 & Dona Ana & José da Silva Mendes Leal Junior \\
\hline $24-10-1857$ & $\begin{array}{c}\text { Os } \\
\text { conspiradores } \\
\text { ou o retrato de } \\
\text { muitos dos } \\
\text { nossos }\end{array}$ & $\mathrm{C}, 1$ & $?$ & $\begin{array}{c}\text { Théophile Marion, Dumersan, Nicolas } \\
\text { Brazier }\end{array}$ \\
\hline $28-10-1857$ & $\begin{array}{l}\text { O Rio de } \\
\text { Janeiro: verso e } \\
\text { reverso }\end{array}$ & C,2 & Luiza (viúva de idade) & José Martiniano de Alencar \\
\hline $5-11-1857$ & $\begin{array}{l}\text { O demônio } \\
\text { familiar }\end{array}$ & $\mathrm{C}, 4$ & $\begin{array}{l}\text { Maria (mãe de } \\
\text { Eduardo) }\end{array}$ & José Martiniano de Alencar \\
\hline $30-11-1857$ & $\begin{array}{l}\text { Adrienne } \\
\text { Lecouvreur }\end{array}$ & $C D, 5$ & $\begin{array}{l}\text { A marquesa / La } \\
\text { marquise }\end{array}$ & E. Scribe e Legouvé / Maria Velluti \\
\hline $19-12-1857$ & O crédito & C,5 & Dona Antonia & José de Alencar \\
\hline $25-12-1857$ & $\begin{array}{l}\text { A cigana de } \\
\text { Paris }\end{array}$ & $D, 5$ & $\begin{array}{l}\text { Zizi Quebra-nozes / } \\
\text { Zizi-Casse-Noisette }\end{array}$ & $\begin{array}{c}\text { Gustave Lemoine e Paul de Kock / } \\
\text { Maria Velluti }\end{array}$ \\
\hline $2-1-1858$ & $\begin{array}{l}\text { Um casamento } \\
\text { em miniatura }\end{array}$ & $\mathrm{C}, 1$ & $?$ & E. Scribe e G. Delavigne [?] \\
\hline $2-1-1858$ & $\begin{array}{l}\text { Os pobres de } \\
\text { Paris }\end{array}$ & $\mathrm{D}, 7$ & Reine Bigot & Edouard Brisebard e Eugene Nus \\
\hline $6-1-1858$ & $\begin{array}{l}\text { E eu sem } \\
\text { casaca! }\end{array}$ & $\mathrm{C}, 2$ & Genoveva & $?$ \\
\hline $23-1-1858$ & $\begin{array}{l}\text { Os folgazões de } \\
\text { Paris }\end{array}$ & $\mathrm{D}, 5+8 \mathrm{Q}$ & $\begin{array}{l}\text { Henriqueta de Luzzy / } \\
\text { Henriette de Luzzy }\end{array}$ & Xavier de Montépin \\
\hline $21-2-1858$ & $\begin{array}{c}\text { A velhice } \\
\text { namorada } \\
\text { sempre leva } \\
\text { surriada }\end{array}$ & OP C,2 & $\begin{array}{c}\text { Tia Perpétua das } \\
\text { conveniências } \\
\text { (vendedora de capilé) }\end{array}$ & Francisco Xavier Pereira da Silva \\
\hline $30-5-1858$ & $\begin{array}{l}\text { As asas de um } \\
\text { anjo }\end{array}$ & $\mathrm{D}, 4+\mathrm{Pr}+\mathrm{Ep}$ & Margarida & José Martiniano de Alencar \\
\hline
\end{tabular}




\begin{tabular}{|c|c|c|c|c|}
\hline DATA & TÍTULO & $\begin{array}{l}\text { GÊNERO,AT } \\
\text { OS }\end{array}$ & PERSONAGEM & $\begin{array}{l}\text { AUTOR/ } \\
\text { TRADUTOR }\end{array}$ \\
\hline $22-8-1858$ & $\begin{array}{l}\text { Os três } \\
\text { boticários }\end{array}$ & $C, 3$ & ? & Lockroy e Anicet Bourgeois / ? \\
\hline $1-10-1858$ & A graça de Deus & DV,5 & Marquesa de Sivry / & Adolphe D'Ennery, Gustave Lemoine. \\
\hline $24-10-1858$ & $\begin{array}{l}\text { A mulher do } \\
\text { povo }\end{array}$ & $\mathrm{C}, 2$ & $\begin{array}{l}\text { Maria Joana / Marie } \\
\text { Jeanne }\end{array}$ & $\begin{array}{c}\text { Dumersan e Alexandre / Francisco } \\
\text { Gonçalves }\end{array}$ \\
\hline $\begin{array}{c}6-11- \\
1858\end{array}$ & $\begin{array}{l}\text { O inimigo das } \\
\text { mulheres }\end{array}$ & $\mathrm{C}, 3$ & $\begin{array}{l}\text { Hortência (atriz) / } \\
\text { Ortensia }\end{array}$ & $\begin{array}{l}\text { Carlo Goldoni / } \\
\text { Maria Velluti }\end{array}$ \\
\hline $27-11-1858$ & $\begin{array}{l}\text { Protheu } \\
\text { moderno }\end{array}$ & $C, 5$ & Miquelina & Justino de Figueiredo Novaes \\
\hline $14-12-1858$ & Se Deus quiser & $C, 3$ & $\begin{array}{c}\text { Sra. Pinson } \\
\text { (estalajadeira) }\end{array}$ & $\begin{array}{c}\text { Jean-François Bayard e Edmond De } \\
\text { Biéville / ? }\end{array}$ \\
\hline $19-12-1858$ & $\begin{array}{l}\text { Por direito de } \\
\text { conquista }\end{array}$ & C,3 & $\begin{array}{l}\text { Sra. Jorge / Mme } \\
\text { George }\end{array}$ & $\begin{array}{c}\text { Ernest Legouvé / José Joaquim Vieira } \\
\text { Souto }\end{array}$ \\
\hline $15-1-1859$ & $\begin{array}{c}\text { As surpresas do } \\
\text { sr. José da } \\
\text { Piedade }\end{array}$ & $\mathrm{R}, 2+4 \mathrm{Q}$ & "Política" & Justino de Figueiredo Novaes \\
\hline $11-1-1859$ & $\begin{array}{l}\text { A cabeleira do } \\
\text { meu tio }\end{array}$ & $\mathrm{C}, 1$ & $\begin{array}{c}\text { Gertrudes (ama de } \\
\text { leite) }\end{array}$ & Charles Nuitter e Louis Duchesne / ? \\
\hline $17-2-1859$ & $\begin{array}{l}\text { [Monólogo de } \\
\text { adeus] }\end{array}$ & * & * & Juana Manso de Noronha \\
\hline
\end{tabular}

Legenda: C=comédia; D=Drama; Q=Quadro; T=Tragédia; Pr.=Prólogo; Ep.=Epílogo; DV=Dramavaudeville; R=Revista; Op.C=Ópera-cômica. Os algarismos referem-se ao número de atos.

\section{Referências}

CAMILO, Vagner. Drummond: da Rosa do Povo à Rosa das Trevas. São Paulo: Ateliê Editorial, 2001.

COLEÇÃO DE JORNAIS (1830-1860). Hemeroteca Digital, Biblioteca Nacional Brasileira.

CYMBRON, Luísa. Francisco de Sá Noronha (1820-1881): um músico português no espaço atlântico. Lisboa: CESEM: Húmus, 2019.

FARIA, João Roberto. O teatro realista no Brasil: 1855-1865. São Paulo: Perspectiva, 1993. 
NORONHA, Juana Manso de. Los misterios del Plata. Biblioteca Virtual Universal, 2003.Disponível em: https://biblioteca.org.ar/libros/71176.pdf

NORONHA, Juana Manso de. Mistérios del Prata: romance histórico contemporâneo. In: Jornal das Senhoras. Rio de Janeiro, 1 de janeiro de 1852, n.1 a 4 de julho de 1852, n.27.

NORONHA, Juana Manso de A família do Comendador. In: A Imprensa. Rio de Janeiro, 1853.

NORONHA, Juana Manso de. A mulher do artista. In: A Imprensa. Rio de Janeiro, 1852, edição de 6 a 15.

NORONHA, Juana Manso de. As consolações. Rio de Janeiro: Typographia Dous de Dezembro, 1856.

NORONHA, Juana Manso de. Negócios do Rio da Prata. Rio de Janeiro, Diário do Rio de Janeiro, 19 de janeiro de 1858, ed. 17, p. 2.

NORONHA, Juana Manso de. Páginas da mocidade: memórias das guerras civis do Rio da Prata de 1838 a 1841. Diário do Rio de Janeiro, edições de 294 a 308 de 1858.

NORONHA, Juana Manso de. La Revolución de Mayo: 1810. Buenos Aires: Imprenta de Mayo, 1864.

NORONHA, Juana Manso de. La familia del Comendador y otros textos. Buenos Aires: Colihue: Biblioteca Nacional de la República Argentina, 2006.

PRADO, Décio de Almeida. João Caetano, o ator, o empresário, o repertório. São Paulo: Perspectiva, 1972.

SCHAPOCHNIK, Nelson. Edição, recepção e mobilidade do romance Les mystères de Paris no Brasil oitocentista. Varia Historia. Belo Horizonte, Minas Gerais, vol.26, n.44, p.591-617, jul./dez. 2010.

SCHAPOCHNIK, Nelson. D’Os mistérios de Paris aos mistérios do Prata: tradução, imitação e invenção. In: Leitura: Teoria \& Prática. Campinas, São Paulo, v.35, n.71, p.101-113, 2017. 